\title{
O MERCADO SECUNDÁRIO DE SNEAKERS: CONSEQUËNCIAS TRIBUTÁRIAS NO BRASIL
}

\author{
Vírginia Ramos Castilho* \\ Marisa Rossignoli**
}

\section{RESUMO}

Objetiva-se estudar os aspectos tributários do mercado secundário de sneakers (composto por tênis raros, muitas vezes produzidos em edições limitadas) no Brasil, no que tange ao ICMS, ao ISS e ao ganho de capital, por meio de pesquisa bibliográfica e documental. Na redação, utilizou-se o procedimento dedutivo. Justifica-se o presente estudo pela necessidade de se tratar as principais questões tributárias atinentes a esse relevante mercado. Concluiu-se pela incidência do ICMS, do ISS e do imposto de renda, em relação a cada um de seus fatores geradores específicos.

Palavras-chave:Direito e Economia; Ganho de Capital;ICMS; ISS;Mercado Secundário de Sneakers.

\section{THE SNEAKERS SECONDARY MARKET: TAX CONSEQUENCES IN BRAZIL}

\begin{abstract}
The objective of the present work was to study the tax aspects of the secondary market of sneakers in Brazil, regarding ICMS, ISS and capital gain, through bibliographical and documentary research. In writing, the deductive procedure was used. The present study is justified by the need to address the main tax issues pertaining to this relevant market. It was concluded for the incidence of ICMS, ISS and income tax, in relation to each of its specific generating factors.
\end{abstract}

Keywords: Gain of Capital;ICMS; ISS;Law and Economics;Secondary Sneaker Market.

\section{INTRODUÇÃO}

\footnotetext{
*Mestranda em Direito pela Universidade de Marília - UNIMAR/SP. Graduada em Direito pela Universidade Estadual de Mato Grosso do Sul - UEMS, pós-graduada em Direito Administrativo pela Faculdade Campos Elíseos e pós-graduanda em Gestão Pública pela Universidade Federal de Mato Grosso do Sul - UFMS. virginia.mestrado@gmail.com.

** Professora do Programa de Mestrado e Doutorado em Direito da Universidade de Marília - UNIMAR/SP. Graduada em Ciências Econômicas pela UNESP- Araraquara, Mestre em Economia pela PUC-SP e Doutora em Educação pela UNIMEP. Delegada Municipal do Conselho Regional de Economia para o Munícipio de MaríliaSP - Brasil. mrossignoli@ unimar.br. 
O comércio de sneakers raros, isto é, tênis raros, muitas vezes em edições limitadas, especialmente por intermédio da internet, é um mercado bilionário, em constante expansão, que produz grande valorização das fábricas e das grifes de calçados esportivos, que alcançam valores astronômicos, construindo um verdadeiro nicho mercadológico.

Além dos modelos vendidos diretamente pelas marcas, há pessoas especializadas em adquirir os referidos modelos erevender aos colecionadores, com lucratividade. Trata-se de uma atividade comparável ao mercado de capitais em relação a vários aspectos, devendo, claramente, ser tributada.

Por se tratar de um mercado novo, com e evidentes especificidades, especialmente relacionadas à possibilidade de negociação de calçados esportivos em bolsas de mercadorias e futuros, demonstrando suas similaridades em relação aos ativos mobiliários, faz-se necessário determinar qual o seu regimento tributário, até mesmo por se compor tanto de circulação de bens quanto de venda de ativos.

Nesse sentido, o objetivo do presente trabalho foi estudar os aspectos tributários do mercado secundário de sneakers no Brasil, especificamente no que concerne ao ICMS, ao ISS e ao ganho de capital, por intermédio de pesquisa bibliográfica e documental, utilizando-se, na redação, o procedimento dedutivo.

Justifica-se o presente estudo em decorrência da necessidade de se tratar das principais questões jurídicas atinentes a um mercado ascendente, que movimenta bilhões de dólares todos os anos e que, caso se instale no Brasil, com força similar à que demonstra em outros países, deve encontrar uma disciplina constitucional e legal adequada à sua tributação.

\section{A REVENDA DE SNEAKERS COMO ATIVOS MOBILIÁRIOS}

Aquilo que hoje se denomina de mercado secundário de sneakers iniciou-se ainda na década de 1980, a partir das primeiras coleções de calçados esportivos, mormente daqueles lançados em edições limitadas, modelos diferentes dos demais, ou até mesmo modelos comuns, todavia, em materiais e cores exclusivas.

O termo sneakers, antes da instalação da subcultura dos colecionadores, tinha conotações mais gerais, referindo-se, meramente, ao sapato com uma sola de borracha projetado para correr, praticar esportes etc. (LAITASALO, 2013). Aos colecionadores de 
Vírginia Ramos Castilho \& Marisa Rossignoli

sneakers, muitas vezes obsessivos em relação às suas coleções, foi autoconferida, há décadas, uma nomenclatura que bem demonstra esse gosto peculiar: sneakerheads.

Antes valorizada pelas comunidades do centro das cidades e empregando celebridades que pareciam gostar de comprar autenticidade, passou a funcionar para a comercialização em massa de tênis, encerrando a subcultura do tênis como era conhecida, pois as coleções de tênis, de passatempo, tornaram-se um grande negócio (LAITASALO, 2013).

Desse modo, o significado da palavra sneakerheads destacou-se de seu sentido original, em decorrência do fato de ter se expandido mundialmente, tendo deixado os centros das grandes cidades americanas e alcançado todo o planeta. O aumento do número de sneakerheads tem influência direta na indústria dos calçados esportivos, tendo aumentado diametralmente os valores das marcas que lançam modelos exclusivos.

Assim, até mesmo aquelas pessoas que não utilizam os sneakers para a prática esportiva ou atlética adquirem esses modelos raros, tanto para colecioná-los quanto para revendê-los a preços exorbitantes.

Muitas vezes, uma marca fabrica um tênis em número altamente limitado, produzindo um ar de exclusividade ao redor de seu produto, o que produz elevada demanda decorrente do simples fato de existirem poucos pares. Até mesmo tênis disponíveis em excesso são vendidos, em virtude do efeito bola de neve, que deriva da influência de um consumidor sobre os outros. Em qualquer caso, os tênis se esgotam (CASSIDY, 2018).

Esse grupo de colecionadores deu origem a um mercado, que movimenta bilhões de dólares, gerando lucros significativos para as grandes marcas de calçados e para os investidores individuais.

É um exemplo de fenômeno quase que exclusivo do mercado de tênis high-end, no qual os consumidores pagam quantias exorbitantes por tênis esportivos, sem a intenção de usá-los para a finalidade pretendida, tomando meticuloso cuidado com sua aquisição, ou usando-os em ocasiões especiais ou, até mesmo, nunca (CASSIDY, 2018).

O mercado de sneakers produz lucros e valorização não apenas para as grifes e fabricantes, como, também, para pessoas físicas e empresas especializadas em adquirir esses calçados e revendê-los, com enorme lucratividade aos atuais sneakerheads, situação que criou um genuíno mercado secundário. 
Aspecto relevante da comunidade sneakerheads é o mercado de revenda. Sneakers muito desejados são vendidos instantaneamente após a liberação. Para quem não consegue comprar um produto por ocasião do lançamento, a única opção de aquisição é o mercado de secundário, no qual os tênis são vendidos após a data de lançamento, com uma grande margem de lucro (CASSIDY, 2018).

Em 2016, o mercado secundário gerou mais de U\$1 bilhão em vendas. Em decorrência disso, vários consumidores adquirem os tênis com a intenção expressa de revendê-los(CASSIDY, 2018).

$\mathrm{O}$ atual mercado de sneakers, especialmente em decorrência de seu rápido crescimento e de sua notável lucratividade, em muito se assemelha ao mercado de capitais, equivalendo, nesse sentido, a ativos, móveis ou imobilizados.

Todo ativo financeiro é posto no mercado e inicialmente negociado por meio do mercado primário, no qual ocorre a "canalização direta dos recursos monetários superavitários", por meio da venda inicial das ações emitidas. Nesse setor, as empresas buscam recursos necessários à consecução de seu crescimento, promovendo, a partir do lançamento das ações, a implementação de projetos de investimento e de incremento da riqueza nacional (ASSAF NETO, 2015).

A título de exemplo, o modelo de tênis mais vendido em 2017, o Nike Tanjun, amplamente acessível em qualquer lugar do mundo, custava cerca de U\$65,00. O que justifica a companhia continuar investindo imensos recursos voltados à manutenção da preferência e da fidelidade de pequenos grupos de entusiastas (CASSIDY, 2018).

Isso porque os colecionados, apesar de retratarem apenas uma pequena parte da receita da empresa, tem um papel importantíssimo na valorização da marca (CASSIDY, 2018). Não bastasse os modelos revendidos no mercado secundário representam maior lucratividade, a exemplo do que ocorre nas bolsas de valores e balcões de negócios.

Um dos modelos Air da Nike, padrão, normalmente é vendido em mercados secundários por U\$ 160. Um modelo muito raro pode custar mais de U\$20.000. Quando os tênis de edição limitada são lançados, as pessoas acampam nas filas durante dias para obter um par, o que oportuniza um lucro alto e rápido, que pode até levar alguns a subornar os empregados das lojas (HYMAN, 2018). 
Vírginia Ramos Castilho \& Marisa Rossignoli

Além disso, há um mercado de ações não oficiais, o StockX, que reúne informações sobre os hábitos de compra da comunidade para fornecer valores atualizados de mercado para diferentes modelos e cores (CASSIDY, 2018, p. 8), o que corrobora as semelhanças entre os mercados secundários de sneakers e de valores mobiliários.

No StockX, os vendedores propõem preços e os compradores podem dar lances, bem como podem ter acesso a dados como números de vendas recentes de toda a internet, volatilidade de preços e altas e baixas. Se uma oferta e uma solicitação coincidem, a venda é realizada (HYMAN, 2018, p. 3).

Referido mercado alcança valor e natureza jurídico-econômica equivalente a verdadeiros ativos financeiros, até mesmo no que concerne às variações de preços e à submissão aos ditames da raridade e da oferta-e-procura, corroborando a afirmação de que os lucros, no interior desse nicho, ocorrem de maneira similar aos procedimentos das bolsas de mercadorias e valores futuros.

Trata-se de um mercado que passou a alcançar brasileiros, tanto colecionadores quanto negociantes desses produtos, que os revendem a preços muito altos, com base nas referidas flutuações mercadológicas, que são capazes de agregar valores a esses bens.

Faz-se necessário, portanto, aferir qual seria o regramento tributário desse mercado no Brasil, a partir dos fatos geradores que dele se possam originar, desde a aquisição dos modelos de tênis até a sua revenda, feita em conformidade com a agregação de valores aferível de sua valorização.

\section{IMPOSTOS INCIDENTES NO MERCADO ELETRÔNICO DE SNEAKERS}

A internet representou uma radical mudança de paradigma em relação a quase todas as espécies de mercados. Ocorre que, em relação ao mercado de sneakers, a web foi (e ainda é) decisiva para o seu crescimento e para sua operacionalidade, já que a maior parte dos negócios é feita on-line.

Há uma presença extremamente grande de coleta de tênis na internet, com uma infinidade de sites que lidam com funções específicas dentro da comunidade. Organizações como Complex, Sole Collector e Nice Kicks fornecem informações sobre os lançamentos. Mercados como Goat e Flight Club fornecem plataformas de compra e venda dos calçados 
(CASSIDY, 2018). O mercado secundário de sneakers, portanto, encontra-se irremediavelmente inserido no comércio eletrônico.

A superveniência do comércio eletrônico teve consequências evidentes no direito, obrigando-o a se adaptar às rápidas mudanças sociais e econômicas ocorridas nas últimas décadas. Um dos ramos jurídicos mais afetados pelo fenômeno foi o direito tributário. Quanto ao mercado secundário de sneakers, por exemplo, essas adaptações também são imperiosas.

$\mathrm{O}$ imposto incidente sobre a circulação de mercadorias e determinados serviços representa a principal fonte de receitas para os Estados brasileiros. Trata-se de um tributo de sistemática extremamente complexa, com farta regulamentação constitucional, legal e infra legal.

A tributação da circulação de mercadorias e outros bens faz-se com base no art. 155, II, da Constituição Federal, cuja competência tributária pertence aos Estados e, em competência cumulativa, ao Distrito Federal, previsto, também, nos $\S \S 2^{\circ}, 3^{\circ}, 4^{\circ}$ e $5^{\circ}$ do dispositivo, assim como no art. 158, IV (BRASIL, 1988).

De acordo com os referidos dispositivos, à União coube criar lei geral sobre o ICMS, por meio de Lei Complementar. Para tanto, foi editada a LC n. 87 de 1996, conhecida como Lei Kandir, a partir da qual cada Estado instituiria o tributo por lei ordinária, regulamentada por meio de decreto, denominado Regulamento do ICMS, que consolidaria toda a legislação vigente no Estado sobre o referido imposto (CARNEIRO, 2013).

Conforme dispõe o art. 155, $\S 2^{\circ}$, XII, $g$, da Constituição, em decorrência de acordo entre dois ou mais Estados da federação serão editados convênios pelo CONFAZ (Conselho Nacional de Política Fazendária) para a concessão de benefícios fiscais (CARNEIRO, 2013).

Levando-se em consideração que os sneakers são, geralmente, importados, não haverá incidência de ICMS e se de Imposto de Importação simplificado (Decreto-Lei n. ${ }^{\circ}$ 1.804/80), ressalvados os Estado onde, além do Imposto de Importação devido, há incidência de ICMS Importação. É o caso de Minas Gerais, Santa Catarina e Rio Grande do Sul.

Vale lembrar que, a forma simplificada do Imposto de Importação incidirá nas importações de até US\$ 3.000,00 (três mil dólares), nos termos do art.1. ${ }^{\circ}$, do Decreto-Lei n. ${ }^{\circ}$ 1.804, de 03 de setembro de 1980. Nos demais casos, segue a legislação vigente competente.

Neste sentido, conforme a portaria MF 156/99 o imposto devido será de 60\% (sessenta por cento) sobre o valor do produto acrescido de frete e seguro. Impende ressaltar 
Vírginia Ramos Castilho \& Marisa Rossignoli

que, as mercadorias entregues na residência do adquirente pelos serviços de correios geralmente, há incidência de ICMS, tendo em vista a circulação do bem, que será calculado e pago, no momento da compra do produto.

\subsection{O conceito de estabelecimento no comércio eletrônico}

O comércio eletrônico atua em todas as camadas do consumo. Desse modo, as negociações no mundo virtual podem ser de mercadorias físicas ou digitais, de forma direta ao consumidor final ou não (indiretas), realizando-se, portanto, tanto entre produtores (B2B), entre produtores e consumidores (B2C), ou entre consumidores (C2C), por exemplo, nos sites de leilão virtual (TEIXEIRA, 2012).

No contexto do comércio eletrônico, as vendas são feitas a partir de um ambiente virtual, intangível fisicamente. Muitas vezes, porém, o empresário que atua nesse contexto sequer tem um ambiente físico, estocando as mercadorias anunciadas em depósitos.

A Organização para Cooperação e Desenvolvimento Econômico -OCDE, todavia, defende que, no cenário virtual, é necessária a utilização de uma lógica tributária que não difere muito da tradicional. (VITA, 2017)

Nesse sentido, estabelecimento permanente seria uma "estrutura jurídico-tributária que equivale a um centro de imputação de rendas", uma "fiç̧ão exclusiva do direito tributário que prescinde da formalização sob o ponto de vista cível e, mesmo, fiscal para sua operatividade" (VITA, 2017, p. 532), o referido autor ainda observa que equivale a uma "[...] base fixa de negócios para realização de um determinando conjunto orientado de atividades, agregando todos os elementos positivos elou negativos da renda, sendo considerada como pessoa jurídica para este fim determinado" (VITA, 2017, p. 532).

O local de armazenamento do produto será o responsável pela emissão da nota fiscal, em decorrência da vedação à circulação de produtos sem nota, infração fiscal e penal. Assim, "[...] o montante arrecadado do tributo é recolhido para o respectivo Estado federal que o integra" (TEIXEIRA, 2012, p. 151).

A página da internet não é, para efeitos fiscais, um estabelecimento comercial, em decorrência da falta de delimitação física, mesmo tendo a Lei Complementar 87 de 1996, determinado o local da tributação como o da operação tributável, utilizando-se, assim, o local 
de saída do bem como da arrecadação (TEIXEIRA, 2012).

\subsection{ICMS na importação por meio da internet}

A incidência do ICMS sobre as operações de importação de bens e mercadoriasé tema controvertido. Apesar de claramente determinada pela Constituição Federal de 1988, a sistemática da incidência do referido tributo nesse contexto é complexa, tendo demandado regulamentação exaustiva.

A entrada de bem ou mercadoria importados do exterior, por pessoa física ou jurídica, ainda que não seja contribuinte do imposto, qualquer que seja sua finalidade, é regulada pelo Art. 155, $\S 2^{\circ}$, IX, $a$, da CF. Esclareça-se que, nos termos do dispositivo, a incidência ocorrerá sobre bens, não apenas sobre mercadorias.

As importações vêm sendo tributadas reiteradamente sob fundamento no art. $155, \S$ $2^{\circ}$, IX, $a$, da Constituição, após sua modificação pela Emenda Constitucional n. 33 de 2001, que fez com que o tributo fosse devido, inclusive, por contribuintes não habituais do imposto (CARNEIRO, 2013).

Diante das polêmicas que caracterizam essa particular incidência, faz-se necessário sua análise, de modo a determinar suas possibilidades no contexto do mercado secundário de sneakers. Nesse contexto, o fato gerador do ICMS-importação é o desembaraço aduaneiro.

A entrega do bem, todavia, somente se fará após a exibição do comprovante de pagamento do imposto. Caso a entrega ocorra antes do desembaraço, considera-se ocorrido o fato gerador nesse momento, devendo a autoridade fiscal exigir a comprovação do pagamento do tributo (BRASIL, 1996).

Também se discute acerca do sujeito ativo do tributo nesse tipo de operação. A Constituição é clara em afirmar a competência tributária dos Estados para a instituição do ICMS. Ocorre que a operação que gera a entrada de mercadoria vinda do exterior para o território nacional provoca uma situação complexa em relação à arrecadação do tributo.

Além do Art. 155, $\S 2^{\circ}$, IX, $a$, da Constituição, surge a discussão acerca do sujeito ativo do ICMS no caso de importação, pois a parte final do dispositivo menciona que o imposto será devido ao Estado de domicílio ou de localização do estabelecimento do destinatário da mercadoria, bem ou serviço (CARNEIRO, 2013). 
Vírginia Ramos Castilho \& Marisa Rossignoli

O Supremo Tribunal Federal, no AgRg no RE 396.559/RJ decidiu que o sujeito ativo da relação é o Estado onde estiver situado o domicílio ou estabelecimento do destinatário, pouco importando se o desembaraço aduaneiro ocorreu em ente federativo diverso.

Já na importação indireta, caracterizada pela existência de um intermediador na importação, a identificação quanto ao real destinatário da mercadoria necessita de exame no caso concreto, pois o ICMS deverá ser recolhido no Estado onde se localiza o destinatário final da mercadoria, mesmo que tenha sido desembaraçada por estabelecimento intermediário (CARNEIRO, 2013).

No entanto, no Brasil, somente os Estados de Minas Gerais, Santa Catarina e Rio Grande Sul, instituíram ICMS Importação.

Quanto à questão do destinatário dos bens importados, para efeito de recolhimento de ICMS, se é o Estado onde serão utilizados ou o Estado onde está sediada a matriz que contratou a importação dos bens, o Superior Tribunal de Justiça entendeu que, nos casos de importação indireta, o ICMS deverá ser recolhido para o Estado onde se encontra o destinatário final da mercadoria, independentemente de ter sido desembaraçada por estabelecimento intermediário, sediado em outra unidade federada (CARNEIRO, 2013).

Assim, considera-se o Estado onde se encontra o destinatário final como sujeito ativo da arrecadação tributária e do cumprimento da política fiscal. A questão relacionada ao sujeito passivo é diretamente resultante do fato gerador do tributo e da sujeição ativa da relação tributária.

Sabe-se que, no direito brasileiro, a sujeição tributária passiva é ampla, disciplinada na Constituição Federal e em normas infraconstitucionais quase que exclusivamente. Verificase, porém, que o assunto é controverso, existindo grande divergência doutrinária em relação ao sujeito passivo do ICMS nas operações de importação.

A Lei Complementar 87, de 1996, com redação dada pela Lei complementar 114, de 2002, dispõe que o ICMS incide sobre a entrada de mercadorias ou bens importados por pessoa física ou jurídica, ainda que não seja contribuinte do tributo (BRASIL, 1996).

Além disso, definiu como contribuinte do imposto, aquele que importe bens do exterior, independentemente de sua finalidade, bem como o destinatário de serviço prestado inicialmente no exterior. É possível que o preço final sugerido pelo fabricante ou importador seja utilizado como base de cálculo (BRASIL, 1996). 
A Lei Complementar 114 surgiu justamente para adaptar a LC 87 à superveniência da Emenda Constitucional número 33, de 2001, que encerrou a questão acerca da possibilidade de incidência do ICMS sobre bens, em sentido amplo, que não se enquadrem no conceito jurídico-tributário.

Ocorre que a questão relativa à instituição do ICMS na importação abrangendo como sujeito passivo o particular adquirente de bens para uso próprio, ainda gerava controvérsias, discussão que deu origem à Súmula 660 do Supremo Tribunal Federal(BRASIL, 2006). Ademais, tornou-se irrelevante a finalidade da importação, desconsiderando-se posterior operação de circulação (LOUREIRO FILHO, 2006).

Apesar disso, o Supremo Tribunal Federal decidiu que, após a Emenda Constitucional número 33, o ICMS incide sobre bens importados por pessoas físicas (BRASIL, 2014), encerrando a questão na jurisprudência do Excelso Pretório.

Assim, com a Emenda Constitucional 33 de 2001, foi ampliado o campo de incidência do ICMS-Importação, passando o tributo a atingir não apenas mercadorias, mas bens móveis de qualquer espécie, desde que submetidos a uma operação de circulação, em sentido jurídico, o que alargou o conceito de contribuinte desse imposto (LEÃO, 2007).

No que se refere especificamente ao mercado secundário de sneakers, portanto, o ICMS incidirá se o contribuinte importar um calçado, pouco importando se visa revende-lo no território nacional ou se adquiriu o bem para imobilizá-lo em sua coleção.

Ainda é necessária, então, a ocorrência de uma operação de venda ou revenda, com transferência da titularidade do bem. Assim, o dispositivo apenas estende o conceito de sujeito passivo do tributo, passando a incluir "[...] qualquer pessoa, fisica ou jurídica, que importe bens em quantidade tal que indique sejam mercadorias (destinadas a comércio ou revenda), fato que o caracterizará como contribuinte, ainda que não habitual" (CARNEIRO, 2013, p. 250).

No RE 474.267-RS, de 2009, o Supremo Tribunal entendeu que a qualidade do importador adquirente é irrelevante, pois, em relação à incidência do ICMS, o bem adquirido é mercadoria, enquadrando-se na hipótese de incidência do tributo.

É constitucional a cobrança do tributo em operações realizadas por pessoas naturais ou jurídicas, que prestem outros serviços que não os de comunicação e transporte, ou seja, que 
Vírginia Ramos Castilho \& Marisa Rossignoli

não pratiquem com habitualidade operações de circulação de mercadorias ou prestação de serviços de comunicação ou transporte intermunicipal e interestadual.

Assim, não há limitação constitucional que vincule indefinidamente a tributação pelos Estados apenas às operações de circulação interna de mercadorias (CARNEIRO, 2013), confirmando, destarte, que o importador será sujeito passivo do tributo, pouco importando a finalidade da operação.

Nesse mesmo sentido, o Convênio ICMS 85 de 2009, em que o CONFAZ buscou uniformizar os critérios para cobrança do ICMS incidente na entrada no país, de bens ou mercadorias importados do exterior, por pessoa física ou jurídica, mesmo que não contribuinte habitual do imposto, independentemente de sua finalidade (BRASIL, 2009).

O imposto resultará da aplicação do percentual equivalente à diferença entre a alíquota interna do Estado onde se deu o desembaraço aduaneiro e a interestadual, ou seja, do Estado destinatário do bem ou serviço adquirido do exterior. O preço de importação deverá ser convertido para moeda nacional (BRASIL, 1996).

Além do que, o valor fixado pela autoridade aduaneira para a base de cálculo do imposto de importação substituirá o preço declarado (BRASIL, 1996). Verifica-se que há diferenças no que tange à construção da base de cálculo, a depender da finalidade da operação ou da natureza jurídica do seu adquirente.

Destacam-se as diferenças na composição da base de cálculo do ICMS-importação no atinente à pessoa adquirente, bem como no que tange à finalidade de sua aquisição. Assim, o IPI pode ser incluído na base de cálculo do ICMS se o produto não se destinar à industrialização ou comercialização, ou se a operação se der entre contribuintes e nãocontribuintes do ICMS, situação que se aplica aos casos em que o produto se destina a consumo ou ao ativo fixo do adquirente (PAULSEN; MELO, 2012).

No contexto do mercado secundário de sneakers, via de regra, o IPI deverá compor a base de cálculo do ICMS, se for adquirido o calçado colecionável por pessoa física. Caso seja vendido, todavia, para empresa especializada, o IPI não será parte da base de cálculo, tendo em vista a finalidade ulterior de comercialização do produto.

De acordo com a Resolução 13, de 2012, do Senado Federal, a alíquota do ICMS em operações interestaduais é de quatro por cento (4\%), aplicável a bens e mercadorias importados, após seu desembaraço aduaneiro, desde que não tenham sido submetidos a 
processo de industrialização, ainda que tenham sido submetidos a qualquer processo de transformação, beneficiamento etc. (BRASIL, 2012).

Não se aplica, no entanto, aos bens que não tenham similar nacional, ou a bens produzidos em conformidade com processos produtivos básicos, hipóteses nas quais os sneakers não se enquadram. É imperioso, também, determinar para qual Estado da federação deverá ser recolhido o tributo.

O fato de os bens importados transitarem unicamente no Estado destinatário não é motivo para se cogitar de exclusiva incidência do ICMS nesse Estado, pois a circulação jurídica não é concretizada com um sujeito passivo localizado em outro Estado (importador). A regra do Art. 11, I, $d$, do Decreto-lei 87 de 1996, que afirma que o local da operação de importação é do estabelecimento onde ocorreu a entrada física da mercadoria ou bem, ou o domicílio daquele que o adquiriu, é inconsistente (PAULSEN; MELO, 2012).

A Fazenda Nacional, pela Secretaria-Executiva da Comissão Técnica Permanente do ICMS (COTEPE), afirmou que a designação contida no Art. 11, I, $d$, da Lei Complementar 87, de 1996, apenas determina a fixação de responsabilidade tributária, de acordo com os Arts. 121 a 134 do Código Tributário Nacional (PAULSEN; MELO, 2012).

Desse modo, geralmente, o ICMS-importação deverá ser recolhido no Estado no qual se encontra domiciliado o adquirente do bem ou da mercadoria ou o contratante do serviço sobre o qual incidirá o referido tributo.

Se o estabelecimento realiza a venda eletronicamente, por meio de página hospedada em provedor situado no Brasil ou no estrangeiro, mas possui depósito em determinado Estado da federação, altera-se o beneficiário da arrecadação, que passa a ser o referido Estado no qual se encontra armazenado o produto. Nesse caso, a tributação seguirá o mesmo sistema de comércio físico, diminuindo-se apenas o custo operacional (TEIXEIRA, 2012).

No caso do mercado secundário de sneakers, assim, caso o vendedor tenha depósito no Brasil para estocagem de bens, a incidência dar-se-á na forma própria para o comércio eletrônico internacional, de modo que o sujeito ativo do tributo será o Estado no qual se encontra o domicílio tributário do adquirente.

Além da obrigação de pagar o tributo, prestação pecuniária compulsória, em moeda ou outro valor que nela se exprima, há obrigações de fazer que resultam da incidência do ICMS sobre a operação de circulação de mercadoria ou de contratação do serviço, a exemplo 
Vírginia Ramos Castilho \& Marisa Rossignoli

da necessária emissão da respectiva nota fiscal.

Assim, se o desembaraço aduaneiro se verificar em unidade da Federação distinta daquela do importador, o recolhimento do ICMS será feito em Guia Nacional de Recolhimento de Tributos Estaduais (GNRE), que deverá indicar a unidade federada beneficiária, salvo no caso de unidade da Federação com a qual tenha sido celebrado e implementado o convênio com a Secretaria da Receita Federal do Brasil (RFB), voltado ao débito automático do imposto em conta bancária indicada pelo importador (BRASIL, 2009).

Ademais, a partir de 10 de junho de 2013 as empresas estão obrigadas a discriminar nas notas fiscais o valor dos tributos incidentes na operação. Até mesmo a importação de uma mercadoria via correio por uma pessoa física é tributada. Evidente que, em decorrência de a fiscalização pelos correios ocorrer por meio de amostragem, é possível que uma mercadoria chegue ao destino sem ser tributada (BERSELLI, 2016).

No contexto do mercado secundário de sneakers, porém, é possível que a aquisição se dê entre pessoas domiciliadas no território nacional, no mesmo Estado ou em unidades federadas diversas.

\subsection{ICMS nas operações de vendas no território nacional}

Apesar de, em regra, os sneakers chegarem ao país por intermédio de importações, é possível que, em decorrência da frenética expansão do mercado, exista um revendedor no território nacional, proprietário de um determinado modelo exclusivo ou raro, que o revenda a outro residente no Brasil.

Nessa hipótese, faz-se necessário aferir se a operação de circulação desse bem ocorrerá dentro de um só Estado federado ou entre unidades diferentes. Suponha-se que um revendedor de sneakers, sediado em um determinado Estado, venda um exemplar a uma empresa ou a um colecionador domiciliado no mesmo ente federado.

Se a mercadoria é vendida para um contribuinte do imposto, por exemplo, do revendedor para o lojista, dentro do mesmo Estado, incidirá a alíquota interna, bem como aplicar-se-á a não cumulatividade das operações. Se a mercadoria é vendida para alguém que não é contribuinte do imposto, por exemplo, o consumidor final, dentro do mesmo Estado, incidirá a alíquota interna. (TEIXEIRA, 2012). 
Nas vendas eletrônicas entre empresas, conhecidas como $B 2 B$, recolhe-se integralmente o ICMS para o Estado produtor, em operações dentro do mesmo Estado, ou parcialmente, por meio da alíquota interna, em operações interestaduais, aplicando-se a não cumulatividade. Nas vendas feitas diretamente do produtor ou fornecedor ao consumidor final (B2C), o ICMS é recolhido para o Estado no qual foi emitida a nota fiscal, correspondente ao local de saída da mercadoria.

Nas compras diretas pelo consumidor via internet, o ICMS é recolhido no Estado de origem do produto, pois o ato de aquisição de produto pelo consumidor final, é tratado como venda de produto para adquirente não contribuinte do imposto, adotando-se, então, a alíquota interna para o Estado de origem do produto (TEIXEIRA, 2012).

Caso a empresa tenha tanto o depósito quanto o sítio da Internet no mesmo Estado da Federação, se o adquirente estiver no referido ente federado, o ICMS será recolhido integralmente nesse Estado. Trata-se, portanto, de uma incidência simples, na qual apenas um Estado recolherá o tributo.

Em sentido oposto ao exemplo anterior, imagine-se um revendedor de sneakers exclusivos ou raros, sediado em um determinado Estado da federação, que negocia um item com uma empresa ou com um colecionador domiciliado em outro ente federado. Não há diferença acerca da carga tributária para o empresário entre uma venda realizada por um estabelecimento físico e uma venda virtual.

Há, contudo, diferenças relacionadas à arrecadação do ICMS gerada pelo $e$ commerceno caso de vendas interestaduais, pois, nesse caso, a arrecadação do ICMS recolhido é "partilhado" entre o estado de origem e o estado de destino da mercadoria. Em função dessa procura de um equilíbrio entre a origem (venda) e o destino (consumo), para que cada estado participante na operação de e-commerce tenha direito a uma parcela do ICMS arrecadado, foi promulgada a Emenda Constitucional no 87, de 17 de abril de 2015.

A responsabilidade pelo pagamento do diferencial de alíquota em operação mercantil de importação para o consumidor final foi delimitada no Art. 155, II, §2. ${ }^{\circ}$, VIII, da Constituição, aplicando-se às vendas no comércio eletrônico (BRASIL, 1988).

Após a Emenda Constitucional 33 de 2001, a alíquota interestadual será adotada para tributar o consumidor final, contribuinte ou não do imposto dividida a responsabilidade pelo 
Vírginia Ramos Castilho \& Marisa Rossignoli

recolhimento entre o destinatário, se for contribuinte do imposto, e o remetente, se o destinatário não for contribuinte (BRASIL, 1988).

Nos casos de vendas telepresenciais ou pela internet, a partir da promulgação da Emenda Constitucional no 87, em 17 de abril de 2015, o ICMS deve ser recolhido tanto para o Estado de origem, como para o Estado de destino da mercadoria, por meio do denominado “diferencial de alíquota” (BERSELLI, 2016).

De acordo com a EC nº 87/2015, até 2019, o Estado de destino deverá dividir esse valor com o estado de origem, de forma que será devido o diferencial de alíquotas na operação interestadual destinada a não contribuinte do ICMS. Assim, o remetente deverá tributar a operação com a alíquota interestadual e, ainda, recolher o diferencial (BERSELLI, 2016).

Dessa forma, várias possibilidades de sujeição ativa compartilhada entre dois Estados da Federação se delineiam, a depender da localização do depósito dos bens ou mercadorias e da unidade da federação na qual se encontra o adquirente.

Antes da alteração introduzida pela Emenda Constitucional 87 de 2015, se a venda se dirigisse a outro Estado, incidiria alíquota externa do Estado produtor, menor do que a interna, bem como a não cumulatividade nas operações. Deveria ser recolhida a diferença entre a alíquota externa do Estado produtor e a interna, do Estado consumidor, para este. Se a venda fosse feita para um consumidor final, para outro Estado, incidirá a alíquota interna do Estado produtor (TEIXEIRA, 2012).

Caso a empresa tivesse depósito e sítio da Internet em Estados diversos, o ICMS seria repartido entre o Estado de origem da mercadoria e o do destino. Caso o adquirente fosse consumidor final, de outro Estado, o ICMS seria recolhido integralmente para o Estado de origem.

Situação diversa ocorrerá se empresa, depósito e sítio de Internet estivessem em locais diversos: se o adquirente fosse o consumidor final, o imposto seria recolhido no Estado de onde saísse o produto, no qual se encontrasse o depósito de mercadoria, a ele cabendo a emissão da nota fiscal; se fosse adquirida por contribuinte, parte do ICMS (alíquota externa) ficaria para o Estado no qual a mercadoria se encontrasse armazenada, e a diferença da alíquota ficaria para o Estado no qual se encontrasse o adquirente, respeitada, porém, a não cumulatividade (TEIXEIRA, 2012). 
Assim, o ICMS sempre seria recolhido para o Estado de origem da mercadoria, pouco importando a localização da matriz da empresa vendedora, o local de instalação do computador do qual se operou a compra ou do provedor de Internet no qual o site da Internet se encontra hospedado (TEIXEIRA, 2012).

Nesse sentido, o Supremo Tribunal Federal decidiu, na ADI 4628, que o ICMS incide sobre as operações interestaduais, pelo Estado de destino, caso os consumidores finais não sejam contribuintes do imposto (BRASIL, 2014). Ocorre que, no contexto do mercado ora estudado, outros tributos também incidirão, porém, sobre outros fatos geradores.

Após a entrada em vigor da referida Emenda, na venda interestadual para consumidor final, o vendedor recolhe o DIFCON que, progressivamente, cresce em proporção para o Estado destinatário. Em 2015, seria 20\%, em 2016, 40\%, em 2017, 60\% e, em, 2018, $80 \%$ a favor do Estado destinatário, enquanto o restante se destinaria ao Estado de origem. A partir de 2019, 100\% deverá ser recolhido para o Estado destinatário.

\section{A TRIBUTAÇÃO SOBRE O GANHO DE CAPITAL}

Nota-se que as características do mercado secundário de sneakers permitem equipará-lo ao comércio de valores mobiliários, operado por meio de bolsas de valores ou de balcões de negócios, especialmente em decorrência da possibilidade de se obter lucros gigantescos a cada negociação, bem como de amargar consideráveis prejuízos.

Em 27 de julho de 2016, um par de tênis Nike Air Jordan IV, apelidado de undefeated, com apenas setenta e dois pares produzidos, foi comprado por U\$18.500,00 por um colecionador desconhecido, na StadiumGoods, uma loja de Nova York que trabalha exclusivamente com revenda de tênis. Assim, o modelo foi vendido com lucro de 9250\% sobre seu preço original de varejo, de U\$200,00. (CASSIDY, 2018).

Evidente que essa adição de capital não passaria impune no que respeita à sua tributação, até porque qualquer renda deve ser tributada, adquirida sob qualquer título que seja, independentemente de sua origem ou regulamentação.

A Lei 7.713, de 1988, determina a tributação dos rendimentos e ganhos de capital, sobre o rendimento bruto, correspondente ao produto do capital, bem como qualquer acréscimo patrimonial, inclusive no que se refere à alienação de bens ou direitos de qualquer 
Vírginia Ramos Castilho \& Marisa Rossignoli

natureza, considerando ganho "a diferença positiva entre o valor de transmissão do bem ou direito e o respectivo custo de aquisição corrigido monetariamente” (BRASIL, 1988).

A Instrução normativa SRF no 84, de 2001 considera ganhos de capital "a diferença positiva entre o valor da alienação de bens ou direitos e o respectivo custo de aquisição", percebidos por pessoas físicas decorrentes de operações realizadas em bolsas de mercadorias ou assemelhadas, em relação, inclusive, a operações de compra e venda (BRASIL, 2001).

Contribuintes do tributo são as pessoas físicas que aufiram ganho de capital na alienação de bens. A incidência do imposto de renda ocorrerá à alíquota de quinze por cento (BRASIL, 2001). A Lei 8.981 de 1995, alterada pela Lei 13.259 de 2016, que determina alíquotas progressivas para essa incidência (BRASIL, 1995).

Esse acréscimo de capital será fiscalizado por meio do programa Ganhos de Capital, nos termos da instrução normativa RFB n 1792 de 2018 (BRASIL, 2018). Desse modo, o ganho de capital, no contexto do mercado secundário de sneakers, será tributado por alíquota mínima de quinze por cento, incidente sobre o acréscimo patrimonial, equivalente à diferença positiva entre o valor da alienação do bem e o respectivo custo de aquisição.

Vale lembrar que, de acordo com a MP 252 de 2004, fica isento do tributo o ganho de capital de até $\mathrm{R} \$ 35.000,00$ (trinta e cinco mil reais), nos termos do art. 35 da referida Medida Provisória. Acima desse valor, a alíquota aplicada sobre o ganho de capital de 15\% (quinze por cento).

Como o mercado secundário desneakers tornou um mercado muito lucrativo, haverá ganho de capital tributável atribuído àquela pessoa física que obtiver lucro (diferença entre o valor de revenda e o valor de aquisição) acima de $\mathrm{R} \$ 35.000,00$ (trinta e cinco mil reais), o que é plenamente possível dentro do universo dos sneakers.

\section{CONCLUSÃO}

O crescimento dos sneakerheads influencia diretamente a indústria dos calçados esportivos, aumentado consideravelmente os valores das marcas, já que até mesmo as pessoas que não utilizam os sneakers podem adquiri-los para coleção ou revenda.

Existem pessoas físicas e empresas que adquirem esses calçados para revende-los, com enorme lucratividade, criando um verdadeiro mercado secundário. 
Assemelha-se, substancialmente, ao mercado de capitais, inclusive no que se refere à lucratividade, à competitividade e à oscilação dos preços, que faz com que os sneakers alcancem valor e natureza jurídico-econômica equivalente à dos ativos financeiros. Nessa circunstância, a internet representou evidente evolução mercadológica.

O mercado secundário de sneakers está inserido no comércio eletrônico, que teve consequências incontáveis para o direito tributário. Quanto ao ICMS, tributo extremamente complexo, tem por fato gerador a circulação de mercadorias e a prestação de serviços específicos, excluídos da incidência do ISSQN.

O imposto também incide sobre as operações ou prestações que se iniciam no exterior. Seu fato gerador é a circulação de mercadoria ou bem ou a prestação de serviço em sentido jurídico, que não é diferente no contexto do comércio eletrônico, que atua em todas as camadas do consumo.

Pelo fato de que as operações ocorrem a partir de ambientes virtuais, faz-se necessário revisar o conceito de estabelecimento comercial que, entretanto, no caso específico da incidência do ICMS, tem pequena importância comparado à dolocal de armazenamento. Em relação às operações de importação, todavia, a complexidade é evidente.

A Lei Complementar 114, ao adaptar a LC 87 à Emenda Constitucional número 31, encerrou a discussão sobre a possibilidade de incidência do ICMS sobre bens em sentido amplo. Quanto ao mercado secundário de sneakers, o ICMS incidirá se o contribuinte importar um calçado, pouco importando se visa revendê-lo ou imobilizá-lo em sua coleção.

Quanto à base de cálculo, em regra, o IPI comporá a base de cálculo do ICMS, se for adquirido o bem colecionável por pessoa física; se, todavia, for adquirido por empresa revendedora, o IPI não será parte da base de cálculo, em decorrência da finalidade ulterior de comercialização.

O ICMS-importação deverá, usualmente, ser recolhido no Estado no qual se encontra domiciliado o adquirente do bem ou da mercadoria ou o contratante do serviço. No caso do mercado secundário de sneakers, dificilmente o vendedor terá depósito no Brasil e, nessa circunstância, a incidência dar-se há na forma própria para o comércio eletrônico internacional.

É possível, entretanto, que a aquisição se dê entre pessoas domiciliadas no território nacional, situação na qual será necessário aferir se a operação ocorrerá em um só Estado 
Vírginia Ramos Castilho \& Marisa Rossignoli

federado ou entre unidades diferentes. Se um revendedor de sneakers, sediado em um determinado Estado, vender um exemplar a uma empresa ou a um colecionador domiciliado no mesmo ente federado, será verificada uma incidência simples, na qual apenas um Estado será o beneficiário do tributo.

Caso um revendedor de sneakers, sediado em um Estado da federação, negocie um item com uma empresa ou com um colecionador domiciliado em outro ente, o ICMS recolhido será "partilhado" entre o estado de origem e o estado de destino da mercadoria. É possível, também, a incidência do ISSQN.

No comércio eletrônico, os bens, mercadorias e serviços são permanentemente expostos na internet, podendo o consumidor adquiri-los diretamente, ou em leilões virtuais. Assim, é possível que o imposto incida sobre a atividade de hospedagem do site, de propaganda dos produtos e em relação aos leilões virtuais.

O mercado secundário de sneakers, comparável que é ao comércio de valores mobiliários, ocasionará adição de capital que deve ser tributada. Por esse ângulo, incidirá alíquota mínima de quinze por cento, referente ao IR, sobre o acréscimo patrimonial, equivalente à diferença entre o valor da alienação e o custo de sua aquisição.

Conclui-se, portanto, que, caso o mercado secundário de sneakers se instale no Brasil, sua exação já se encontra possibilitada pelo sistema tributário nacional, em relação à circulação de bens, à prestação de serviços e ao ganho de capital, sem a necessidade de se recorrer a qualquer sorte de analogia em prejuízo dos contribuintes.

\section{REFERÊNCIAS}

ASSAF NETO, Alexandre. Mercado de capitais. 13. ed. São Paulo: Atlas, 2015.

BERSELLI, Daniel. Tributação e e-commerce. Brasília: SEBRAE, 2016.

BRASIL. Código Tributário Nacional. 1966. Dispõe sobre o Sistema Tributário Nacional e institui normas gerais de direito tributário aplicáveis à União, Estados e Municípios. Disponível em: www.planalto.gov.br. Acesso em: 20 nov. 2018.

BRASIL. Constituição da República Federativa do Brasil. 1988. Disponível em: www.planalto.gov.br. Acesso em: 20 nov. 2018. 
BRASIL. Lei 7.713 de 1988. Altera a legislação do imposto de renda e dá outras providências. Disponível em: http://www.planalto.gov.br/ccivil_03/LEIS/L7713.htm. Acesso em: 20 nov. 2018.

BRASIL. Lei 8.981 de1995. Altera a legislação tributária Federal e dá outras providências. Disponível em: http://www.planalto.gov.br/ccivil_03/LEIS/L8981.htm. Acesso em: 20 nov. 2018.

BRASIL. Lei Complementar 87 de 1996. Dispõe sobre o imposto dos Estados e do Distrito Federal sobre operações relativas à circulação de mercadorias e sobre prestações de serviços de transporte interestadual e intermunicipal e de comunicação, e dá outras providências. (LEI KANDIR) Disponível em: http://www.planalto.gov.br/ccivil_03/LEIS/LCP/Lcp87.htm. Acesso em: 20 nov. 2018.

BRASIL.Lei complementar 114de 2002. Altera dispositivos da Lei Complementar $n^{\circ}$ 87, de 13 de setembro de 1996, que dispõe sobre o imposto dos Estados e do Distrito Federal sobre operações relativas à circulação de mercadorias e sobre prestações de serviços de transporte interestadual e intermunicipal e de comunicação, e dá outras providências. Disponível em: http://www.planalto.gov.br/ccivil_03/leis/lcp/lcp114.htm. Acesso em: 20 nov. 2018.

BRASIL. Conselho Nacional de Política Fazendária. Convênio ICMS 85. 2009. Uniformiza procedimentos para cobrança do ICMS na entrada de bens ou mercadorias estrangeiros no país. Disponível em: www.confaz.fazenda.gov.br/legislacao/convenios/2009/CV085_09. Acesso em: 20 nov. 2018.

BRASIL. Secretaria da Receita Federal. Instrução normativa SRF no 84. 2001. Dispõe sobre a apuração e tributação de ganhos de capital nas alienações de bens e direitos por pessoas físicas. Disponível em:

http://normas.receita.fazenda.gov.br/sijut2consulta/link.action?idAto=14400\&visao=anotado. Acesso em: 20 nov. 2018.

BRASIL. Secretaria da Receita Federal. Instrução normativa RFB n 1792. 2018. Aprova o programa multiplataforma Ganhos de Capital para apuração de resultado sujeito à incidência do Imposto sobre a Renda da Pessoa Física relativo ao ano-calendário de 2018. Disponível em:http://normas.receita.fazenda.gov.br/sijut2consulta/link.action?idAto $=90348 \&$ visao $=$ anota do. Acesso em: 20 nov. 2018.

BRASIL. Senado Federal. Resolução no 13. 2012.Estabelece alíquotas do Imposto sobre Operações Relativas à Circulação de Mercadorias e sobre Prestação de Serviços de Transporte Interestadual e Intermunicipal e de Comunicação (ICMS), nas operações interestaduais com bens e mercadorias importados do exterior. Disponível em: http://www.planalto.gov.br/ccivil_03/_Ato2011-2014/2012/Congresso/RSF-13-2012.htm. Acesso em: 20 nov. 2018. 
Vírginia Ramos Castilho \& Marisa Rossignoli

BRASIL. Supremo Tribunal Federal. ADI 4628. Relator: Ministro Luiz Fux. Publicado em: 17 nov. 2014. Disponível em: www.stf.jus.br. Acesso em: 20 nov. 2018.

BRASIL. Supremo Tribunal Federal. RE 439.796. Relator: Ministro Joaquim Barbosa. Publicado em: 17 mar. 2014. Disponível em: www.stf.jus.br. Acesso em: 20 nov. 2018.

BRASIL. Supremo Tribunal Federal. Súmula 660. Disponível em:http://redir.stf.jus.br/paginadorpub/paginador.jsp?docTP=TP\&docID=5473460. 2006. Relator: Ministro Joaquim Barbosa. Acesso em: 17 mar.2014.

BRASIL. Superior Tribunal de Justiça. RMS 19.064-RS. Relatora: Ministra Eliana Calmon. Disponível em: www.stj.jus.br. Acesso em: 20 nov. 2018.

CARNEIRO, Claudio. Impostos federais, estaduais e municipais. 4. ed. São Paulo: Saraiva, 2013.

CASSIDY, Nicholas George. The effect of scarcity types on consumer preference in the high-end sneaker market. Honors Thesis. Science in Business Administration. Appalachian State University: 2018.

EMERENCIANO, Adelmo da Silva. Tributação no comércio eletrônico. São Paulo: Thomson Iob, 2003.

HYMAN, Dan. A NASDAQ for Sneakerheads? A way to tame the high-end market. New York Times, p. 3, 7 jul., 2018.

KERR, Roberto Borges. Mercado financeiro e de capitais.São Paulo: Pearson Prentice Hall, 2011.

LAITASALO, Riku. Sneakerheads: influencers of industry or insignificant insiders? A business history on the collectible sneaker market. Thesis. Master's Thesis. Masters of Science in Economics and Business Administration. Aalto University: School of Business 2013.

LEÃO, Cristiano Maciel Carneiro. A Emenda Constitucional 33/01 e o "novo" ICMSimportação: manutenção da "transferência de titularidade" como núcleo constitucional da materialidade do ICMS-importação. Dissertação Mestrado em Direito. São Paulo: Pontifícia Universidade Católica de São Paulo, 2007.

LOUREIRO FILHO, Mário Hermes Trigo de. Alteração da competência tributária e reforma constitucional: o ICMS na importação de bens e a EC 33/01. Dissertação. Mestrado em Direito. São Paulo: Pontifícia Universidade Católica de São Paulo, 2006.

PAULSEN, Leandro; MELO, José Eduardo Soares de. Impostos federais, estaduais e municipais. 7. ed. Porto Alegre: Livraria do Advogado, 2012. 
SILVA, Mário José. Tributação do comércio eletrônico no plano internacional - uma visão geral Revista Tributária e de Finanças Públicas, v. 38, p. 9-17, maio-jun., 2001.

TEIXEIRA, Ricardo Santiago.ICMS no comércio eletrônico. Revista Tributária e de Finanças Públicas, v. 105, p. 143-189, jul.-ago., 2012.

VITA, Jonathan Barros. Economia digital disruptiva: (re)analisando o conceito de estabelecimento tributário no direito brasileiro e internacional. In: SOUZA, Priscila de; CARVALHO, Paulo de Barros. (Org.). Racionalização do sistema tributário. São Paulo: Noese, 2017, v. 1, p. 519-536. 